\title{
Knowledge grounded on pure reasoning
}

\author{
Luis Rosa* \\ (Forthcoming in Pacific Philosophical Quarterly)
}

\begin{abstract}
In this paper I deal with epistemological issues that stem from the hypothesis that reasoning is not only a means of transmitting knowledge from premise-beliefs to conclusion-beliefs, but also a primary source of knowledge in its own right. The idea is that one can gain new knowledge on the basis of suppositional reasoning. After making some preliminary distinctions, I argue that there are no good reasons to think that purported examples of knowledge grounded on pure reasoning are just examples of premise-based inferences in disguise. Next, I establish what kinds of true propositions can to a first approximation be known on the basis of pure reasoning. Finally, I argue that beliefs that are competently formed on the basis of suppositional reasoning satisfy both externalist and internalist criteria of justification.
\end{abstract}

\section{Reasoning as a source of knowledge}

Reasoning is usually taken to be an ampliative cognitive resource, in that it allows us to expand or increase our knowledge on the basis of knowledge we already have. Accordingly, contemporary epistemology of reasoning has for the most part concentrated on the transmission of knowledge/justification from premise-beliefs to conclusion-beliefs. 1 But reasoning can arguably also generate new knowledge, or knowledge that is not based on any previous propositional knowledge. Purported examples of that phenomenon include those in which the reasoner learns the truth of a conditional as a result of suppositional reasoning: e.g. one concludes that Some feminists are philosophers under the scope of the supposition that Lucy is a feminist philosopher, and infers from there that If Lucy is a feminist philosopher then some feminists are philosophers. In these cases, the subject's inferential belief does not seem to be grounded on any premise-beliefs, but rather on a piece of suppositional reasoning. Reasoners would be able to extract knowledge from the sheer workings of their own minds. ${ }^{2}$

\footnotetext{
* Assistant Professor at CONCEPT, University of Cologne. Email: fsopho@gmail.com

Acknowledgments: This research was funded by the Alexander von Humboldt Foundation. I am thankful to Branden Fitelson, Andrea lacona, Vicenzo Crupi, Ted Shear, Catharine Saint-Croix and Niels Skovgaard-Olsen for their comments on a previous version of this paper, presented at the Reasoning Club 2017 at the University of Torino. I would also like to thank my colleagues Sven Bernecker, Amy Floweree, Lisa Benossi and Jakob Ohlhorst for commenting on this paper in our weekly meeting at CONCEPT, University of Cologne.

${ }^{1}$ See e.g. Boghossian (2003), Wright (2003), Brown (2003), Lasonen-Aarnio (2008) on the transmission of warrant/justification through deductive inference, and Hawthorne (2004), Klein (2004) and Dretske (2005) on the principle of closure of knowledge under competent deduction.

${ }^{2}$ When I write that the subject comes to know or that the subject learns that If Lucy is a feminist philosopher then some feminists are philosophers through suppositional reasoning, I imply that the subject didn't already know that, or at least she didn't know it under the guise or mode of presentation of that conditional. So representing the subject's state of
} 
Some epistemologists have characterized the power we have to know things by means of suppositional reasoning as some sort of byproduct of our more down-to-earth competence to handle doxastic input-see Williamson (2007, p. 162) and Rumfitt (2008, p. 63). E.g. that I am equipped to infer that No robots are cats from my belief that No cats are robots means that I am also equipped to conclude that No robots are cats under the scope of my supposition that No cats are robots. The types of reasoning that we use to draw inferences on the basis of our beliefs can also be used to draw conclusions from hypotheses or suppositions that we make 'in the armchair' (the same reasoning capacities that allow us to process information online-i.e. on the basis of knowledge we already have-are carried over to offline information-processing as well). As a result, we can also form new beliefs on the basis of those processes of suppositional reasoning, e.g. the belief that If no cats are robots then no robots are cats.

Again, to the extent that those beliefs constitute knowledge, we have reasons to believe that reasoning is also a source of knowledge, and not just a means of transmitting it from premise-beliefs to conclusion-beliefs. (Whenever I use the term 'reasoning' without qualification here, I just mean deductive reasoning).$^{3}$ More specifically, the relevant hypothesis here is that suppositional reasoning is a source of knowledge for humans. That hypothesis does not just amount to the claim that knowledge on the basis of suppositional reasoning is possible, with no qualification of a modal base. I.e. the hypothesis is not just that it is possible in principle for some kind of creature or some kind of informationprocessing machinery to generate knowledge through suppositional reasoning. Rather, the claim is that it is possible for creatures with the kind of psychology that we humans possess to have knowledge through suppositional reasoning. This qualification will assumed to be in place from now on, and it will prove important for some of the issues to be discussed below.

Even though the idea that reasoning is also a source of knowledge or justification has already been put forward elsewhere in the literature (see e.g. Schechter 2010, Balcerak Jackson and Balcerak Jackson 2013 and Dogramaci 2016), it has not been fully explored yet. This paper is supposed to take the issue a bit further. In particular, I will address the following questions here:

(a) Is it indeed accurate to say that those beliefs that result from suppositional reasoning

belief/knowledge through the standard machinery of possible worlds semantics would not capture the relevant epistemic phenomena here. For-as that form of representing cognitive states would have it-the subject already knew logical truths such as the aforementioned conditional all along, with or without performing any piece of suppositional reasoning. The reader should then think here of more fine-grained ways of individuating the contents of doxastic attitudes.

${ }^{3}$ According to Harman (1986, Ch. 1-2) the notion of deductive reasoning, understood as a certain type of cognitive process or reasoned change in view, is a misleading one. The danger here is that of conflating reasoning in this sense with argument or proof (more on this below) and, consequently, conflating also the rules of reasoning with the rules of logic. But we can draw the distinction between deductive and non-deductive reasoning without conflating reasoning and argument. The relevant distinction here is a distinction between two general types of cognitive processes, e.g.: (i) when one reasons deductively from $R$ (a set of propositions) to $\phi$, one is thereby disposed to revise one's attitudes toward $R$ upon learning/supposing that $\phi$ is not true, whereas this functional property is not present in non-deductive reasoning, or (ii) when one performs deductive reasoning from $R$ to $\phi$, one is committed to the claim that it is impossible for all the members of $R$ to be true and $\phi$ false (which may as well be a false claim), whereas one exhibits no such commitment when one reasons in a non-deductive way. An anonymous referee has suggested that the distinction could also be drawn thus: (iii) a piece of reasoning from $R$ to $\phi$ is deductive when the subject assigns a probability of 1 to $\phi$ conditional on the conjunction of all members of $R$, and it is non-deductive when the subject assigns a high but non-maximal probability to $\phi$ conditional on the conjunction of all the members of $R$. 
and are maintained on that basis are not also based on any premise-beliefs?

(b) What other propositions (besides logical truths) can be known on the basis of suppositional reasoning?

(c) Do beliefs formed and maintained on the basis of suppositional reasoning satisfy externalist criteria of epistemic justification? What about internalist ones?

Question (a) is meant as a challenge to the claim that reasoning is also a primary source of knowledge: perhaps those purported examples of beliefs based on suppositional reasoning are just premise-based beliefs in disguise. In Section 3, I will argue that this challenge ultimately fails. Question (b) is the topic of Section 4, where I argue that suppositional reasoning can also give us knowledge of non-logical 'conceptual' truths (e.g. that If Descartes has doubts then Descartes is a thinking being). When presented with the claim that reasoning is a source of knowledge, those who take epistemic justification to be a necessary condition for knowledge are bound to raise question (c). This is the topic of Section 5.

\section{Inference, reasoning, suppositional reasoning}

In the way I am using these notions here, inference is a subtype of reasoning. ' $S$ infers that $\phi$ on the basis of $R$ ' (where $R$ is a set of premises) entails ' $S$ reasons from $R$ to $\phi$ '; and the simpler one ' $S$ infers that $\phi$ ' (which makes no reference to reasons or premises) entails something like ' $S$ reasons her way to the conclusion that $\phi$ '. The distinguishing feature of inference is that, when one performs an inference, one either ends up forming a new belief or giving additional support to a belief that one already had even before the inference. In this sense, both ' $S$ infers that $\phi$ ' and ' $S$ infers that $\phi$ on the basis of $R$ ' entail ' $S$ believes that $\phi$ ' 4

So all inference is reasoning, but not all reasoning is inference. l.e. ' $S$ reasons from $R$ to $\phi$ ' does not entail ' $S$ infers that $\phi$ on the basis of $R$ '; for the former does not entail ' $S$ believes that $\phi$ ', whereas the latter does. One can reason with suppositions instead of beliefs, without thereby believing the conclusions that one derives under the scope of one's suppositions. When I make the supposition that Angela and Barbara are the same person and develop the consequences of that supposition-e.g. that Angela lives in Berlin if and only if Barbara lives in Berlin-I need not believe that those consequences do in fact obtain. In fact, when performing that piece of suppositional reasoning, I can at the same time believe that Angela and Barbara are not the same person and that Angela lives in Berlin whereas Barbara does not.

Call the conclusions that are drawn under the scope of suppositions 'suppositional conclusions'. Suppositional conclusions are ultimately attached to a supposition or series of suppositions. That relation is transitive: if $\phi$ is attached to $\psi$ and $\psi$ is attached to

\footnotetext{
${ }^{4}$ See Staffel (2013) for the question whether there can also be inference/reasoning with degrees-of-belief or credences. For the sake of simplicity, I deal only with inferential beliefs here, rather than inferential degrees-of-belief. Taking a stand on Staffel's question would take us too far away from the main topic of this paper.
} 
$\sigma$, then $\phi$ is attached to $\sigma$. Suppose again that I make the supposition that Angela and Barbara are the same person; I conclude from that that If Angela lives in Berlin then Barbara lives in Berlin; then I conclude from the latter that Either Angela does not live in Berlin or Barbara does. In this case, both conclusions are suppositional conclusions: for both of them are ultimately attached to, or they are both drawn under the scope of my initial supposition that Angela and Barbara are the same person.

Again, even though ' $S$ reasons from $R$ to $\phi$ ' does not entail ' $S$ believes that $\phi$ ', a reasoner can always form beliefs on the basis of pieces of suppositional reasoning. E.g., on the basis of the two-step process of suppositional reasoning mentioned in the previous paragraph, I may end up forming the belief that Angela and Barbara are the same person only if either Angela does not live in Berlin or Barbara does. I will not attempt to explicate the notion of basing relation here; in general, epistemologists talk about beliefs being based on other beliefs, on perceptual/introspective experiences and memories, sometimes also 'intuitions' or rational insights (see e.g. Bon Jour 2014). In a more or less standard way of understanding the basing relation-i.e. as a causal relation (which may or may not be analyzed in terms of counterfactuals) - it would not appear to be problematic to include pieces of suppositional reasoning among the types of things or processes a belief can be based on. To a first approximation, then, $S$ bases her belief that $\phi$ on a given piece of suppositional reasoning only if $S$ believes that $\phi$ because (causal explanation) $S$ has performed that piece of reasoning. ${ }^{5}$

In saying that a belief is based on a piece of suppositional reasoning, I do not mean to imply that the basing relation is a one time thing, as if the belief were based on the piece of suppositional reasoning only at the time in which it is formed as a result of that process of reasoning. Basing is understood here as a relation that is stable over time: the reasoner's belief can still be based on the relevant process of suppositional reasoning even if that process is not occurrent or even 'fresh' in the reasoner's mind anymore (in the causal account, the fact that the subject has performed that piece of reasoning will still be part of the explanation why the subject holds the relevant belief) ${ }^{6}$ What if the subject forgets the original process of reasoning?

The question must be disambiguated. In one sense of ' $S$ forgets the original process of reasoning', it means that $S$ has forgotten that she has performed that process. But in order for that to be the case $S$ must have been previously aware that she has performed that process to begin with, and that is not the basis of one's judgment in the kinds of cases I am describing here (i.e. the basis is not a state of belief/awareness that one has performed a piece of suppositional reasoning, but rather the piece of suppositional reasoning itself). In another sense of ' $S$ forgets the original process of reasoning', it means that $S$ has forgotten how to reason in the way she used to do before. If $S$ performs a piece of suppositional reasoning at a time $t_{i}$, we would normally expect $S$ to be able to go through that process of suppositional reasoning again at some time $t_{j>i}$, absent any substantial changes in $S$ 's cognitive system (e.g. S's being brain dead). Accordingly, we might take the availability of the same reasoning process at time $t_{j>i}$ to be necessary for

\footnotetext{
${ }^{5}$ For an overview of the literature on the basing relation, see Korcz (2012).

${ }^{6}$ I thank Catharine Saint-Croix and also an anonymous referee for calling my attention to these points here.
} 
the truth of the claim -as made in $t_{j>i}$-that the subject's belief is based on that piece of suppositional reasoning. So if in $t_{j>i}$ the subject has forgotten how to reason in the way she did to reach her inferential belief in $t_{i}$, then we might say that it is not true in $t_{j>i}$ that the subject's belief is based on that piece of reasoning.

I also call a belief that is based on a piece of suppositional reasoning an inferential belief. Just as a reasoner can infer that certain things are true from her available reasons, so she can infer that certain things are true on the basis of pieces of suppositional reasoning. One can make an analogy here between inferential processes and derivations in a proof system. In some derivations one first writes certain formulas down without proving them, and one derives further conclusions that ultimately depend on those formulas; there are other derivations, however, in which one proves things that do not depend on any formula in any previous line of the proof: one just needs to use the derivation rules of the system to derive them. And yet we also call the latter ones 'proofs' or 'derivations', even though their conclusions were not drawn from previous formulas. Similarly for inferences: some of them are drawn on the basis of premise-beliefs, others on the basis of pieces of suppositional reasoning.

But the analogy should not be taken too far. We do indeed use derivation rules in order to perform proofs or derivations, e.g. when doing the homework for the logic class; but that we follow inferential rules when we perform inferences in general is a controversial empirical hypothesis. There has been a substantial amount of criticism in contemporary psychology of reasoning against that hypothesis, and it is far from being the most received view among cognitive psychologists today. 7 Furthermore, ordinary inference precedes proof: to some extent, formal logic is a rational reconstruction or an idealization of natural inferential processes. This becomes more or less evident when logicians abstract away from particular examples of good inferences expressed in natural language and establish that a schematic rule that captures some relevant feature in common among all those natural language inferences should be regarded as valid in their formal systems. As elsewhere, however, the rational reconstructions or idealizations involved in logic are not identical to that which they reconstruct or idealize over. So, again, we should not take the analogy between proof and inference too far (more on this below).

I have given some examples of suppositional reasoning in which the suppositional conclusion is drawn under the scope of suppositions, and those suppositions only. There are other processes of suppositional reasoning, however, in which one draws the suppositional conclusion from one's suppositions combined with one's beliefs. 8 E.g. I know that $a^{2}+b^{2}=c^{2}$, where $a, b, c$ represent the sides of a right triangle, the latter one being the hypotenuse (this is the Pythagorean theorem); I make the supposition that $T$ is a right triangle such that $a_{T}=3$ and $b_{T}=4$; under the scope of that assumption, I derive the conclusion that $T$ 's hypotenuse is $c_{T}=5$. But in order to reason my way to

\footnotetext{
7Among the objections to the hypothesis that we reason by means of inferential rules are the so-called 'content-effects' in reasoning tasks (we exhibit different responses to tasks with the same formal structure but different contents-see Johnson-Laird and Byrne 2002 for discussion) and the fact that easy inferences which engage a large amount of background knowledge would otherwise be very complex or computationally intractable if the hypothesis that we reason by means of inferential rules were true (see Chater, Heit and Oaksford 2005 for an overview of 'mental logics' theories of reasoning and their advantages/disadvantages over other theories).

${ }^{8}$ See also Dogramaci $(2016$, p. 2) for this observation.
} 
that conclusion I use my knowledge of the Pythagorean theorem-i.e. that conclusion is partly based on a previous belief of mine. And yet it is still a suppositional conclusion, for ultimately it also depends on a supposition about the properties of a certain triangle. So when I infer that If $T$ is a right triangle such that $a_{T}=3$ and $b_{T}=4$, then $T$ 's hypotenuse is $c_{T}=5$ on the basis of that piece of suppositional reasoning, my inferential belief is also grounded on my belief that $a^{2}+b^{2}=c^{2}$.

In order to distinguish a process of suppositional reasoning that includes both suppositions and doxastic contents among its premises from one that includes only suppositions, I will call the latter 'purely suppositional' reasoning. Inferential beliefs that are based on purely suppositional processes of reasoning are not based on any premise-beliefs or reasons: they are grounded on pure reasoning.

\section{Suppositional reasoning vs. reasons}

Crispin Wright (2014, p. 29) claims that, when one establishes that a conditional is true by means of conditional proof, one's conclusion is actually grounded on a previous judgment to the effect that one has validly derived the consequent from the antecedent of the target conditional. In general, the term 'premise-discharging inference' would be a misleading one, insofar as the inferential processes that go under that label do not really do away with all the premises. Does that conflict with the claim that one could come to know things purely on the basis of suppositional reasoning?

Wright is presumably talking about proofs or derivations here-things that we do when we do logic and mathematics; he is not talking about the non proof-theoretic, ordinary type of cognitive process that humans go through when they form new beliefs after exploring the consequences of their suppositions. Ordinary reasoners would not need to use the rule of conditional proof in order to infer e.g. that If Lucy is a feminist philosopher then some feminists are philosophers on the basis of a piece of suppositional reasoning that goes from the supposition that Lucy is a feminist philosopher to the conclusion that Some feminists are philosophers. Such reasoners need not be in the business of proving things at all (not all reasoners are logicians) $9^{9}$

So when it comes to proof-theoretic contexts, Wright's claim certainly seems to be true: in those contexts one uses the system's derivation rules in quite a self-conscious, explicit manner (in fact one usually writes it down which rules were applied to which lines of the proof). It is quite plausible to say that, e.g. when I assume that something of the form $(F a \wedge G a)$ is true, derive from that a conclusion of the form $\exists x(F x \wedge G x)$ by the rule of existential generalization, and finally apply the rule of conditional proof in order to prove the conditional $(F a \wedge G a) \rightarrow \exists x(F x \wedge G x)$, thus discharging the initial assumption, I do so also on the basis of my previous judgment that I have validly derived $\exists x(F x \wedge G x)$ from $(F a \wedge G a)$.

But we should resist the temptation to over-intellectualize ordinary reasoning and carry that description over to our analysis of it. In order to form beliefs on the basis of

\footnotetext{
${ }^{9}$ See Harman (1986, Ch. 2) again for the dangers of identifying reasoning/inference with proof or argument.
} 
suppositional reasoning, reasoners do not need to engage in the controlled, self-conscious kind of activity that is involved in proof-theoretic contexts. And so I take it that Wright's observation does not conflict with the claim that an ordinary reasoner could come to know things on the basis of purely suppositional reasoning, since his observation seems to be about the activity of establishing that a certain conditional is true by means of conditional proof-it is not about forming beliefs on the basis of suppositional reasoning in general (including non proof-theoretic reasoning).

Indeed, the defender of the hypothesis that reasoning is a source of knowledge for creatures like us can perfectly grant that the fact that a human subject could borrow and use those rules from natural deduction or axiomatic systems to prove things from the empty set of premises does not give any support to that hypothesis. For, in trusting the natural deduction/axiomatic system rules and performing derivations with them, the subject is to a certain extent outsourcing the cognitive labor. This means not only that the subject's inferences here are also based on her judgments about the soundness or other properties of those rules-but also that she is not doing the reasoning herself (the subject just needs to have a list of rules written down somewhere and recognize certain formulas as matching the pattern in those rules, thus generating new formulas).

But perhaps some people might still have the 'intuition' that a belief formed through suppositional reasoning only counts as knowledge if that belief is also grounded on the reasoner's judgement that her suppositional reasoning was valid. Consider Ana who is pregnant with twins; they are going to be called 'Andy' and 'Beacon' respectively. Then Ana reasons as follows: she supposes that Andy will be born before Beacon and, under that supposition, she concludes that Andy will be slightly older than Beacon; as a result, she infers that If Andy is born before Beacon, then Andy will be slightly older than Beacon. Now it is at least possible for Ana to know the latter proposition on the basis of such a process (I discuss the possibility of knowledge of non-logical 'conceptual' truths through suppositional reasoning in more detail below). Of course, in order for that to be the case, Ana's cognitive performance must manifest legitimate inferential competence. But the point here is just that if her belief in the conditional is to be based on her anterior judgment that she has validly derived the conclusion that Andy will be slightly older than Beacon from her supposition that Andy is born before Beacon, then she must have knowledge of that higher-order claim as well. Yet how can we reasonably expect Ana to have knowledge of such a complex claim before she can have knowledge of the target conditional?

In general, one needs to engage more cognitive resources in order to know that one has validly derived $\psi$ from $\phi$ than one needs to know that If $\phi$ then $\psi$. The former but not the latter requires one to have a concept of validity, as well as it requires one to do whatever it is that one needs to do in order to have knowledge of what follows from what. Furthermore, knowing that one has validly derived $\psi$ from $\phi$ requires one to reflect on one's cognitive processes, whereas knowing that If $\phi$ then $\psi$ does not (not unless $\phi$ and $\psi$ are themselves about one's reasoning process, of course). But Ana does not need to use any information about what she did or did not do during her process of reasoning in order for her to competently reach the conclusion that If Andy is born before Beacon 
then Andy will be slightly older than Beacon; and she does not need to have a concept of/knowledgeable views about what validly follows from what either. But she would need both of these things in order to know that she has validly derived Andy will be slightly older than Beacon from her supposition that Andy will be born before Beacon. Thus, to require the latter to be a premise or reason on the basis of which Ana believes the target conditional is to set an unreasonably high bar for her to have knowledge of that very conditional.

All of this is compatible with saying that, even though Ana does not use the claim that she has validly derived Andy will be slightly older than Beacon from her assumption that Andy will be born before Beacon as a premise or a reason to believe that If Andy is born before Beacon then Andy will be slightly older than Beacon, she is still disposed to believe that higher-order claim and use it in support of her belief toward the conditional (if the question is ever raised as to what reason is there for her to believe that the conditional is true). And so there is a sense in which that higher-order claim might be internally accessible to Ana (assuming she has the relevant concept of validity, etc.). But that Ana is disposed to believe that higher-order claim upon reflection does not mean that she already believes it and uses it as a premise for her original conclusion. ${ }^{10}$ So it should at least be possible for Ana to gain knowledge of that conditional solely on the basis of suppositional reasoning, even if she does not use that higher-order claim as a premise or reason to believe the conditional.

\section{Other truths knowable through reasoning alone}

Now one might wonder what more exactly is the class of truths that can be known by means of purely suppositional reasoning. Some of the defenders of the view that suppositional reasoning is a source of knowledge/justification also seem to think that reasoning processes whose sequences of contents can be formalized as reductio ad absurdum arguments are among the types of reasoning that generate new knowledge or justification (see Dogramaci 2016, p. 2).

Here is one example. I make the supposition that It is not the case that the universe is either finite or infinite; under the scope of that supposition, I conclude that The universe is not finite (i.e. it is infinite) and it is not infinite; given that contradiction, I infer that The universe is either finite or infinite, thus rejecting my initial supposition. Call these types of reasoning 'reductio types of reasoning'. As I am using this notion here, a reductio type of reasoning happens when one makes a supposition that $\phi /$ not- $\phi$, concludes something with the form $\psi$ and not- $\psi$ under the scope of that supposition, and ends up inferring that not- $\phi / \phi]^{11}$ So the claim would be that beliefs that are generated through reductio

\footnotetext{
${ }^{10}$ See Audi (1994) for the important distinction between a disposition to believe and a dispositional belief.

${ }^{11}$ Of course, there is more than one characterization of the reductio ad absurdum mode of reasoning in the literature. Accordingly, alternative proof systems will feature different rules that go by the name 'reductio ad absurdum' (where the difference here is a syntactic one, having to do with what kinds of operations one is allowed to perform on the relevant symbolic items). But here I mean by 'reductio types of reasoning' just those kinds of reasoning that exhibit the aforementioned structure. The alternative type of reasoning to be presented below could also be called a reductio type of reasoning, but this is just a terminological choice.
} 
types of reasoning are not based on any previous beliefs either. That would mean that the class of propositions that can be known on the basis of purely suppositional reasoning includes much more than just conditionals (or: it includes much more than propositions that are under the guise/mode of presentation of a conditional). One can also learn, e.g. the truth of disjunctive and negative claims in this way (or: one can also learn the truth of propositions under disjunctive/negative guises or modes of presentation), as well as identity claims, etc.

In response to this, however, one might suggest instead that beliefs that are formed through reductio types of reasoning are not solely based on purely suppositional reasoningthey are also based on previous beliefs. The idea would be that the inferential belief that one forms through a reductio type of reasoning is also based on a belief to the effect that the contradictory claim is false (i.e. the one that is deduced from one's initial supposition). When one makes the supposition that $\phi$, concludes that $(\psi$ and not- $\psi)$ under the scope of that supposition and finally infers from there that not- $\phi$, one's belief that not- $\phi$ appears to be based on both: the piece of suppositional reasoning and a belief to the effect that not- $(\psi$ and not- $\psi)$.

According to this proposal, reductio reasoning is but one instance of a more general pattern: the reasoner makes the supposition that $\phi$ and concludes that $\psi$ under the scope of that supposition; but since the reasoner believes that not- $\psi$, she ends up inferring that not- $\phi$. Or: the reasoner makes the supposition that not- $\phi$ and concludes from there that $\psi$; but since the reasoner believes that not- $\psi$, she ends up inferring that $\phi$. E.g. consider the following reasoning process: I make the supposition that Oscar Wilde is the same as John Ruskin and John Ruskin is the same as Lewis Carroll; I conclude from there that Oscar Wilde is the same as Lewis Carroll; but since I know that Oscar Wilde is not the same as Lewis Carroll, I infer on that basis that It is not the case that both, Oscar Wilde is the same as John Ruskin and John Ruskin is the same as Lewis Carroll (at least one of these conjuncts is false). Quite clearly, in this case my inferential belief is based not only on the relevant piece of suppositional reasoning - but also on my previous belief that Oscar Wilde is not the same as Lewis Carroll. What reason is there to think that reductio reasoning is essentially different from that?

This reaction would not be that surprising, given how vague ascriptions of beliefs are. But we can sidestep that controversy and still maintain (with Dogramaci 2016) that purely suppositional reasoning gives us knowledge of those claims that can be inferred through reductio modes of reasoning. And that is because it is possible for one to make the same suppositions and draw the same inferences as those of reductio types of reasoning but without obviously making use of any previous premises of the form not- $(\psi$ and not- $\psi)$. l.e., instead of believing that not- $\phi$ on the basis of a piece of suppositional reasoning that goes from $\phi$ to $(\psi$ and not- $\psi$ ), one might reason as follows: one makes the supposition that $\phi$, concludes that not- $\phi$ under the scope of that supposition (which means that $\phi$ was an inconsistent supposition to begin with), and ends up inferring that not- $\phi$ on the basis of that piece of suppositional reasoning (after all, even the supposition that $\phi$ is the case leads to the conclusion that not- $\phi$ is the case). And similarly for those cases in which one makes the supposition that not- $\phi$ and ends up inferring that $\phi$. 
This kind of reasoning can also give us knowledge of first-order quantified claims (e.g. claims of the form There is no $x$ such that $\Phi_{x}$ ) and modal claims (e.g. claims of the form It is not possible that $\phi$ )-and it does so without obviously engaging any beliefs toward claims of the form not- $(\phi$ and not- $\phi)$. After all, claims with that very form can be known in this way. ${ }^{12}$ So we can avoid the controversy over whether inferential beliefs resulting from reductio types of reasoning (as defined above) are based on beliefs toward propositions of the form not- $(\phi$ and not- $\phi)$ and still get the result that purely suppositional reasoning is a source of knowledge of the relevant truths.

Of course, in order for it to be a source of knowledge, one's reasoning from $\phi /$ not- $\phi$ to not- $\phi / \phi$ must be competently performed (only competent reasoning can be a source of knowledge). And so, e.g. if I make the supposition that I am wearing a tuxedo and conclude that I am not wearing a tuxedo under the scope of that supposition, that piece of suppositional reasoning will not give me knowledge of the latter proposition (even if it is true). For my mode of reasoning in this case is presumably not a competent one. To a first approximation, one could try to account for my lack of competence here by pointing out that my reasoning fails to track the alethic properties of/relations among the propositions involved. One competently reasons from the supposition that $\phi$ to the suppositional conclusion that not- $\phi$ only when one's reasoning is properly sensitive to the inconsistency of $\phi$ (which requires $\phi$ to be inconsistent); if one had made a consistent supposition instead, one would not reason in that way. And so when $\phi$ is a consistent proposition, there is no inconsistency for one to be sensitive to. Therefore, I reason in a non-competent way in the example just given.

It is not my goal to explicate the notion of competence in deductive reasoning here. But it is clear that there are more or less plausible ways of doing so-and they will allow us to properly categorize my reasoning from I am wearing a tuxedo to I am not wearing a tuxedo as a non-competent one, and to tell it apart from the good instances of reasoning from suppositions of the form $\phi /$ not- $\phi$ to conclusions of the form not- $\phi / \phi$.

I have also been assuming that one can gain knowledge of non-logical truths through purely suppositional reasoning. E.g. I make the supposition that My desk is red, derive the conclusion that My desk is colored under the scope of that supposition, and finally infer on that basis that If my desk is red then it is colored. There are many other examples of such 'conceptual' truths that can be known in this way: that No squares are circles, that It is not the case that the cat is at the same time dead and alive, that If $a=7$ then $a>2$, etc.

It might be objected that, e.g. my transition from My desk is red to My desk is colored must be mediated by a belief to the effect that All red things are colored-in which case I would not form my belief just on the basis of suppositional reasoning (and similarly for the other 'conceptual' truths mentioned above). Of course no one will deny that that transition can be so mediated; but must it be so mediated, if I am to gain knowledge that If my desk is red then it is colored through that piece of suppositional reasoning? So first I would need to learn that All red things are colored, and only then I could competently deduce that My desk is colored from my supposition that My desk is red.

\footnotetext{
12 I thank an anonymous referee for this observation here.
} 
But how could I come to learn that $A / l$ red things are colored in the first place? One might suggest that it is my sheer competence with the concepts red and colored that gives me knowledge of that proposition. But the sheer conceptual competence unaided by a process of reasoning gives me nothing here (even if a disposition to perform that process of reasoning is constitutive of possessing the relevant concepts-see Boghossian 2003 and Williamson 2007 for two different views on this). I still have to reason, no matter how 'quick-and-easy' it is going to be, in order to come to know that All red things are colored. And so in order for me to reason my way up to All red things are colored, I would have to perform the same kind of suppositional reasoning that originally led me from My desk is red to My desk is colored. I.e. I will assume of an arbitrary object $x$ that $x$ is red and I will conclude under the scope of that supposition that $x$ is colored, without helping myself with the yet-to-be-formed belief that All red things are colored; for that is exactly the conclusion that I am going to draw on the basis of that piece of suppositional reasoning!

There is no good reason to think that I could not come to know that All red things are colored in this way. (If I already had to believe that All red things are colored in order to competently perform the piece of suppositional reasoning from $x$ is red to $x$ is colored and reach the conclusion that All red things are colored on that basis, I would already need to believe the very conclusion of my inference). Again, my reasoning from $x$ is red to $x$ is colored, and from there to the universal generalization that All red things are colored, must be competently performed (if I am to gain knowledge of that universally quantified proposition in this way). E.g. I would not reason in the way I did with red and colored with any old pair of concepts $(f, g)$ such that an object that is randomly picked from the extension of $f$ is also in the extension of $g$; I would reason in the way I did with red and colored only when the following holds: it does not matter which member of the extension of $f$ I pick, it is also in the extension of $g$. My reasoning is sensitive to that feature. (Relatedly, some cognitive psychologists of reasoning take it that being sensitive to and actively searching for counterexamples is constitutive of certain kinds of deductive reasoning-see e.g. Johnson-Laird and Khemlani 2013, pp. 13-15).

Now, since my knowledge that $A / l$ red things are colored could be grounded on the same type of suppositional reasoning as the one that I have used to infer that If my desk is red then my desk is colored, ${ }^{13}$ nothing stops us from saying that I can have knowledge of the latter proposition in that way as well. The objection that I must already know/believe that All red things are colored in order to competently deduce that My desk is colored from My desk is red therefore fails. And so with this kind of objection out of the way, it appears again that one can come to know not only logical truths, but also non-logical 'conceptual' truths on the basis of purely suppositional reasoning.

\footnotetext{
${ }^{13}$ This is not to say that the two pieces of suppositional reasoning are identical: in the former case, I conclude that an arbitrary object $x$ is colored under the scope of my supposition that $x$ is red, whereas in the latter case, I conclude that My desk is colored under the scope of my supposition that My desk is red. The point is that these are two pieces of reasoning of the same type.
} 


\section{Justification through reasoning: internalism and externalism}

Assume that knowledge requires epistemic justification; if it is possible for one to know things on the basis of purely suppositional reasoning, then it should also be the case that the beliefs that are based on suppositional reasoning are thereby justifiably held.

As far as externalist criteria of justification go, those beliefs can certainly count as justified. E.g. the process of drawing inferences on the basis of suppositional reasoning can be a reliable type of belief-forming process, and thus the beliefs that one forms in this way will count as justified by process-reliabilist standards. ${ }^{14}$ That is clearly the case when both the piece of suppositional reasoning itself is necessarily truth-preserving and the inferential belief that one forms on the basis of it is consequently true, for all instances of the relevant process-type. Since good reasoning is arguably also an intellectual virtue, and in the target cases one forms one's inferential beliefs because one exercises that virtue, those beliefs will also satisfy virtue-theoretic conditions for epistemic justification (see Sosa 2003, Ch. 9). In fact, I have been assuming here that externalist conditions like these are satisfied in those cases in which one gains knowledge through purely suppositional reasoning. Those conditions were assumed to be in place under the label of a competent way of reasoning.

The question, then, is whether one's inferential belief satisfies internalist criteria of justification when it is reliably/competently formed on the basis of suppositional reasoning. In these cases the belief's justifier itself seems to be a reasoning process: an episode of suppositional reasoning (the term 'justifier' is from Alston 1989, and it is supposed to make reference to the epistemic basis of a belief, or to what is responsible for its justification). One might conclude from this that for certain mentalist accounts of epistemic justification, according to which all justifiers are mental states (see Conee and Feldman 2001), the target beliefs are unjustified; for reasoning processes are not themselves mental states (such as experiences or beliefs). But the conclusion does not follow from that observation. It can be argued that, when a reasoner's piece of suppositional reasoning is competently performed, the reasoner has some kind of non-propositional awareness of/insight into the support relation between her supposition and her suppositional conclusion ${ }^{15}$ And, if the beliefs that reasoners form in the target cases are based on that state of awareness or insight, then they do count as justified by mentalist standards. While we may (fairly) question the existence of such non-propositional states, that possibility is still open to the mentalist.

It might also be suggested that, if that is how the mentalist will make sense of apparently justified beliefs that result from purely suppositional reasoning, then according to the mentalist herself those beliefs are not really based on reasoning; they are rather based on the relevant states of awareness/insight—which seems to undermine the claim that reasoning itself is a source of epistemic status. That observation is somehow otiose,

\footnotetext{
${ }^{14}$ For a seminal formulation of process-reliabilism about epistemic justification, see Goldman (1979).

${ }^{15}$ Fumerton (2015) uses the notion of awareness and Bonjour (2014) the notion of insight into the positive connection between premises and conclusion to establish conditions for inferential justification. Even though both of them are concerned with premise-based inferences, there is no reason why they could not advance these as conditions for competent suppositional reasoning as well.
} 
however. The relevant state of awareness or insight would presumably be constitutive of the piece of suppositional reasoning (perhaps that is how the mentalist will want to distinguish reasoning from mere causation among propositional attitudes). At the end of the day, it does not make much of a difference: it is still the case that we get justified beliefs out of competent suppositional reasoning.

Another way in which a mentalist internalist could embrace the idea that there is knowledge grounded on suppositional reasoning is the following. Start with the claim that facts about what one has justification to believe supervene on what one's mental states are. Now add to that the idea that, just by virtue of possessing the relevant concepts, subjects have justification to believe all those logical and 'conceptual' truths that are knowable through suppositional reasoning. So far this is just about one's having justification to believe things, independently of whether one does actually believe those things (this is what some people call 'propositional justification', as opposed to 'doxastic justification'). The step from having justification to believe to actually justifiably believing logical/conceptual truths is then made possible by suppositional reasoning, which must be properly sensitive to the relevant features of the target concepts (i.e. the features in virtue of which the subject has justification to believe those logical/conceptual truths, and that are constitutive of possessing those concepts). Since possessing concepts is a mental condition, and justification here is determined by sheer concept-possession, this is yet another way in which mentalism might be made compatible with the thesis I have been investigating in this paper ${ }^{16}$

Mentalism is not the only version of internalism about justification out there. There is also a stronger version sometimes called 'access internalism'. The idea here is that justifiers are always internally accessible to subjects who hold justified beliefs, in the sense that the subject can always become aware (by reflection) of the elements that justify her belief ${ }^{17}$ In our discussion about whether beliefs that result from purely suppositional reasoning are actually based on premise-beliefs (Section 3) I remarked that, even though the proposition that one has validly concluded that $\psi$ from one's supposition that $\phi$ need not be a premise or reason on the basis of which one believes that If $\phi$ then $\psi$, it might still be internally accessible to the subject (assuming she has a concept of validity). Since the proposition that one has validly concluded that $\psi$ from one's supposition that $\phi$ is a good reason to believe that If $\phi$ then $\phi$, the access internalist requirement would be satisfied in this case.

Of course, the internalist would take the class of cases in which suppositional reasoning gives rise to justified inferential beliefs to be smaller than the externalist would have it, for the latter will say that one's belief is justified when it is based on reliable/competent suppositional reasoning even if no such reason as that one has validly concluded that $\psi$ from one's supposition that $\phi$ is internally accessible to one, whereas the former will not. But the point is that both the externalist and the internalist make it possible for beliefs that are formed on the basis of purely suppositional reasoning to be justified. The thesis

\footnotetext{
${ }^{16}$ Thanks to an anonymous referee for suggesting this alternative way of reconciling mentalism with the idea of knowledge grounded on suppositional reasoning.

${ }^{17}$ See Pappas (2006) for weak and strong versions of access internalism.
} 
that reasoning is also a source of knowledge does not seem to conflict with either view of epistemic justification.

\section{Concluding remarks}

In this paper I have explored certain problems regarding the idea that reasoning is also a source of knowledge, not only a means of transmitting knowledge from premise-beliefs to conclusion-beliefs. The objection that purported examples of beliefs grounded on suppositional reasoning are actually examples of premise-based inferences was found to be wanting. And so it would appear that a reasoner can indeed extract knowledge from the sheer workings of her (ratiocinative) mind.

I have argued further that we can know not only logical truths on the basis of purely suppositional reasoning, but also non-logical 'conceptual' truths. Reasoning can give us knowledge of a large chunk of the propositions that are traditionally regarded as knowable a priori. A natural next move from here is to ask whether there is still more that can be known on the basis of reasoning alone-perhaps 'philosophical' modal truths, such as If the universe were fully deterministic then there would be no free will (if that is true at all), or Knowledge cannot be merely justified true belief, ${ }^{18}$ or even more mundane counterfactual truths, such as If I had been stabbed in the heart, I would die. That idea is indeed suggested by Balcerak Jackson and Balcerak Jackson's (2013) paper on reasoning as a source of justification. Their example of the former phenomenon is that of a conclusion that results from a thought experiment: one could come to justifiably believe propositions of the form If such-and-such scenario obtains (a scenario described by a fictional vignette) then this-and-that conclusion obtains (one that involves a philosophically relevant concept, e.g. understanding, moral correctness or knowledge). If the transition from the propositions that are expressed by the fictional vignette to the proposition involving the philosophically relevant concept counts as reasoning, then that would be yet another case of knowledge/justified belief (in this case a belief to the effect that the corresponding conditional is true) grounded on suppositional reasoning.

As Balcerak Jackson and Balcerak Jackson themselves point out, however, someone could dispute the claim that the processes that we use to learn those modal truths are reasoning processes properly understood. And that claim has indeed been disputed by Williamson (2007, pp. 143-147). A proper assessment of this issue would require another paper, however, and so I will not defend the claim that those modal truths can also be known on the basis of purely suppositional reasoning here. This question is left for future work.

Finally, I have argued that it is possible for those beliefs that result from purely suppositional reasoning to meet both externalist and internalist criteria of epistemic justification. As far as the condition of epistemic justification for knowledge goes, then, both externalists and internalists could grant that reasoning is also a source of knowledge.

\footnotetext{
${ }^{18}$ I thank Niels Skovgaard-Olsen for calling my attention to this.
} 


\section{References}

Alston, William P. (1989). Epistemic Justification, Ithaca: Cornell University Press.

Audi, Robert N. (1994). 'Dispositional beliefs and dispositions to believe', Nous 28(4): 419-434.

Balcerak Jackson, Magdalena and Balcerak Jackson, Brendan (2013). 'Reasoning as a source of justification', Philosophical Studies 164(1): 113-126.

Boghossian, Paul (2003). 'Blind Reasoning', Proceedings of the Aristotelian Society, Supplementary Volume 77: 115-248.

BonJour, Laurence (2014). 'In Defense of the a Priori', In M. Steup, J. Turri, E. Sosa (eds.) Contemporary Debates in Epistemology (2 ed.), Malden, MA: Wiley Blackwell, pp. 177-184.

Brown, Jessica (2003). 'The Reductio Argument and Transmission of Warrant', In S. Nuccetelli (ed.) New Essays on Semantic Externalism and Self-Knowledge, Cambridge, MA: MIT Press, pp. 117âĂȘ130.

Chater, Nick, Heit, Evan and Oaksford, Mike (2005). 'Reasoning', In K. Lamberts and R. L. Goldstone (eds.) Handbook of Cognition, London: Sage Publications, pp. 297-320. Conee, E. and Feldman, R. (2001). 'Internalism Defended', American Philosophical Quarterly, 38(1): 1-18.

Dogramaci, Sinan (2016). 'Reasoning Without Blinders: A Reply to Valaris', Mind 125(499): 889-893.

Dretske, Fred (2005). 'Is Knowledge Closed Under Known Entailment?', In M. Steup and E. Sosa (eds.), Contemporary Debates in Epistemology, Malden, MA: Wiley Blackwell, pp. 13-26.

Field, Hartry (2009). 'Pluralism in logic', The Review of Symbolic Logic 2(2): 342-359. Fumerton, Richard (2015). 'What the Internalist Should Say to the Tortoise', Episteme 12(2): 209-217.

Goldman, A. (1979). 'What Is Justified Belief?', in G.S. Pappas (ed.), Justification and Knowledge, Dordrecht: Reidel, pp. 1-25.

Harman, Gilbert (1986). Change in View, Cambridge, MA: MIT Press.

Hawthorne, John (2004). Knowledge and Lotteries, Oxford: Oxford University Press.

Johnson-Laird, Philip N. and Byrne, Ruth M. J. (2002). 'Conditionals: A theory of meaning, pragmatics, and inference', Psychological Review 109: 646-678.

Johnson-Laird, Philip N., and Khemlani, Sangeet (2013). 'Toward a unified theory of reasoning', Psychology of Learning and Motivation, 59: 1-42.

Klein, Peter (2004). 'Closure Matters: Academic Skepticism and Easy Knowledge', Philosophical Issues, 14(1): 165-184.

Korcz, Keith Allen (2012). 'The Epistemic Basing Relation', E. N. Zalta (ed.) The Stanford Encyclopedia of Philosophy (Fall 2015 Edition), URL $=<$ https://plato.stanford.edu/ archives/fall2015/entries/basing-epistemic >.

Lasonen-Aarnio, Maria (2008). 'Single premise deduction and risk', Philosophical Studies 141(2): 157-173.

McGee, Van (1985). 'A Counterexample to Modus Ponens', Journal of Philosophy 82(9): 
462-471.

Pappas, George (2006). 'Access Internalism', Croatian Journal of Philosophy 6(2): 159169.

Read, Stephen (1994). 'Formal and Material Consequence', Journal of Philosophical Logic 23(3): 247-265.

Rumfitt, lan (2008). 'Knowledge by Deduction', Grazer Philosophische Studien 77: 6184.

Schechter, Joshua (2010). 'The Reliability Challenge and the Epistemology of Logic', Philosophical Perspectives 24(1): 437-464.

Sosa, Ernest (2003). 'Beyond Internal Foundations to External Virtues', in L. Bonjour and E. Sosa, Epistemic Justification: Internalism vs. Externalism, Foundations vs. Virtues, Malden, MA: Blackwell, pp. 97-170.

Staffel, J. (2013). 'Can there be reasoning with degrees of belief?', Synthese 190(16): 3535-3551.

Williamson, Timothy (2007). The Philosophy of Philosophy, Malden MA: Blackwell Publishing.

Wright, Crispin (2003). 'Some Reflections on the Acquisition of Warrant by Inference', In S. Nuccetelli (ed.) New Essays on Semantic Externalism and Self-Knowledge, Cambridge, MA: MIT Press, pp. 57-77.

Wright, Crispin (2014). 'Comment on Paul Boghossian, "What is inference"', Philosophical Studies 169(1): 27-37.

Yalcin, Seth (2012). 'A Counterexample to Modus Tollens', Journal of Philosophical Logic 41(6): 1001-1024. 